\section{Cutting Apple Fruits Induces Cellulase Activity in the Abscission Zone}

\author{
Daniel L. Ward ${ }^{1}$, Eric P. Beers ${ }^{2}$, Ross E. Byers ${ }^{3}$, and Richard P. Marini ${ }^{3}$ \\ Department of Horticulture, Virginia Polytechnic Institute and State University, \\ Blacksburg, VA 24061-0327 \\ Additional index words. aminoethoxyvinylglycine, naphthaleneacetic acid, preharvest drop, \\ Malus $\times$ domestica
}

\begin{abstract}
Preharvest abscission of apple [Malus $\times$ domestica (L.) Borkh.] fruits causes significant crop loss in many years. In this study, fruit cutting was used to induce abscission in August and September. Abscission zones of 'Redchief Delicious' Mercier strain fruits were sampled $0,2,4$, and 6 days after cutting. Thin-layer-plate assays were developed and used to identify hydrolytic enzymes active in the abscission zone (AZ) after induction. Increased activity of cellulase, but not polygalacturonase, was detected in the AZ following cutting. Cellulase activity was consistently high in AZs 4 days after cutting. Both AVG (652 $\left.\mathrm{mg} \cdot \mathrm{L}^{-1}\right)$ and NAA $\left(10 \mathrm{mg} \cdot \mathrm{L}^{-1}\right)$ applied 2 or 4 days after cutting delayed drop, but NAA delayed drop 1.6 days longer than did AVG. Fruits treated with AVG dropped over a longer period than did control or NAA-treated fruits. Chemical names used: aminoethoxyvinylglycine (AVG); naphthaleneacetic acid (NAA).
\end{abstract}

Apple fruit abscission shortly before harvest is responsible for substantial crop losses in many years. Attempts to control this problem with plant growth regulators have yielded variable results for unknown reasons. If the physiology of abscission was clearly understood, new methods of controlling preharvest losses could be developed. All the physiological details of abscission are not known for any system, but abscission of bean (Phaseolus vulgaris L.) leaf petioles has been studied extensively. The degradation of cell wall polysaccharides by extracellular hydrolases is crucial during bean leaf abscission (del Campillo et al., 1990; Sexton and Roberts, 1982), and the degradation of cell walls in the abscission zone (AZ) is associated with increased cellulase activity (Horton and Osborne, 1967). Ethylene treatments stimulate increased synthesis and activity of cellulase and polygalacturonase (PGase) in the AZ of peach fruit explants [Prunus persica (L.) Batsch.] (Bonghi et al., 1992). Pandita and Jindal (1991) observed increased PGase and cellulase activity in the $\mathrm{AZ}$ of apple fruits induced to abscise with ethephon (2-chloroethylphosphonic acid), an exogenous ethylene precursor.

Inducing fruit abscission by cutting apple fruits on the tree is a useful model system for evaluating responses to growth regulators (Marini and Byers, 1988) and avoids both the confounding effects of ethephon and the need to wait for natural drop. Whether this method of abscission induction involves cellulase activity is unknown. The objectives of this study

\footnotetext{
Received for publication 23 Apr. 1998. Accepted for publication 4 Sept. 1998. The cost of publishing this paper was defrayed in part by the payment of page charges. Under postal regulations, this paper therefore must be hereby marked advertisement solely to indicate this fact.

${ }^{1}$ Graduate Student.

${ }^{2}$ Assistant Professor.

${ }^{3}$ Professor, Cellular and Whole-plant Physiology.
}

were: 1) to develop a simple means to evaluate enzyme activity in the AZ and use it to determine which enzymes are active in cell wall hydrolysis during abscission of cut fruit; and 2 ) to determine if growth regulators can delay abscission when applied after the appearance of hydrolytic activity in the AZ.

\section{Materials and Methods}

Assays for hydrolytic enzyme activity. Trees used in this experiment were 8-and 9-year-old 'Redchief Delicious' (Mercier strain) on M.26 rootstock. Each day from late July through mid-Sept. 1996 and 1997, 18-20 fruits were cut in half transversely through the seed cavity. Five spurs were cut from the tree 0-6 d after fruit cutting to assay for enzyme activity, and free-hand longitudinal sections through the $\mathrm{AZ}$ were cut with a disposable microtome blade.

Assays, based on the work of Saleh-Rastin et al. (1991), were developed for visualizing enzyme activity in the AZ. Thin layers $(\approx 2 \mathrm{~mm}$ thick) of $6 \%$ agarose in $50 \mathrm{~mm}$ acetate buffer $(\mathrm{pH} 5.2)$ were prepared in 6-cm square petri dishes. To detect hydrolytic enzyme activity, $0.2 \%$ substrate was included in the gel. The cellulase substrate was carboxymethylcellulose and the PGase substrate was polygalacturonic acid. The cut surfaces of spur pieces were pressed gently against the gel for $1 \mathrm{~s}$. Pieces of spur $\approx 7 \mathrm{~mm}$ long were pressed against the gel twice in each $1-\mathrm{cm}$ square etched in the petri dish. The plates were then sealed and incubated at $37{ }^{\circ} \mathrm{C}$ for $3 \mathrm{~h}$. Activity of carboxymethyl-cellulase (CM-cellulase) was visualized by staining the plates in a bath of $0.1 \%$ Congo red for $30 \mathrm{~min}$ and destaining by rinsing several times with $1 \mathrm{M}$ $\mathrm{NaCl}$. Areas of substrate hydrolysis were detectable as nonstained regions. Activity of PGase was visualized by staining for $20 \mathrm{~min}$ with $0.05 \%$ ruthenium red and destaining with several rinses of water.
Effects of applying growth regulators after induction. The experiment was conducted on trees of 'Redchief Delicious' (Mercier strain) on M.26 rootstock. All the fruits on three trees were cut in half transversely through the seed cavity on 6 Sept., and sprays of AVG (652 $\left.\mathrm{mg} \cdot \mathrm{L}^{-1}\right)$ or NAA $\left(10 \mathrm{mg} \cdot \mathrm{L}^{-1}\right)$ based on acid equivalent, respectively, were applied to the point of drip with a small hand sprayer 2 or 4 $\mathrm{d}$ after cutting. All sprays contained $0.2 \%$ Tween 20 (Sigma, St. Louis) as a surfactant. Nontreated controls (cut and noncut fruit) were included in the treatment array. Abscised fruits were counted every day until all fruits had dropped and the number of days from cutting to drop was calculated for each fruit.

The experimental design was a randomized complete block with three blocks. Whole trees were blocks, five single-scaffold limbs per tree were the experimental units and 10 fruits per limb were subsamples. The treatment design was an augmented factorial array of two compounds and two application dates augmented with a cut and an uncut control. The data were analyzed using SAS's MIXED Procedure with block as a random effect and treatment as a fixed effect. Preplanned contrasts were used to test the hypotheses of interest.

\section{Results and Discussion}

Assays for hydrolytic enzyme activity. Because results were similar in both years, only results from 1997 will be discussed. Cutting of fruits resulted in abscission within 7-12 d and caused increased cellulase activity in the AZ (Fig. 1). PGase activity was not detectable in the abscission zone (data not shown), but Pandita and Jindal (1991), using different assays, showed that both cellulases and PGases were active in ethephon-induced abscission of apples. The differences in season, environmental factors, and method of induction could explain these different results. Alternatively, transfer of PGase from the tissue to the agarose plate may have been inadequate, or the levels of activity may have been below the level of detection for this assay. We were able, however, to detect $\mathrm{PGase}$ activity in ripening apple fruits (data not shown). Most of the cellulase activity was confined to a narrow band of cells presumably comprising the separation layer (Fig. 1). The increased CM-cellulase activity of the AZ is consistent with results obtained in bean (Horton and Osborne, 1967), peach (Ramina et al., 1993), and tomato (Lycopersicon esculentum Mill.) (Tucker et al., 1993).

Cellulase activity increased following induction and was high in all AZ samples $4 \mathrm{~d}$ after cutting (Fig. 1). On all sampling dates, the time course of cellulase activity development was consistent. The 4-d delay between cutting and appearance of high levels of CMcellulase activity suggests the involvement of a multistage signal transduction pathway and de novo synthesis of cellulase (Bonghi et al., 1992). Points of regulation along this pathway may provide appropriate targets for manipulating apple fruit abscission.

The assays developed for this study were 


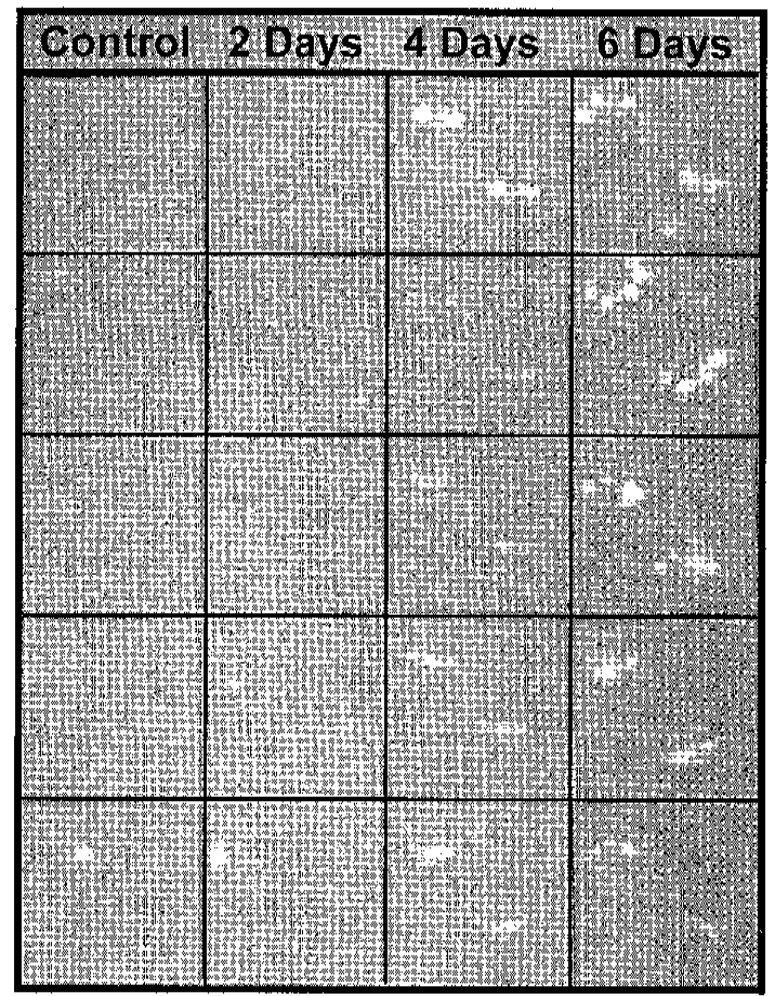

Fig. 1. Assay for CM-cellulase activity of fresh longitudinal sections through apple fruit abscission zones sampled 0 (noncut), 2, 4, and $6 \mathrm{~d}$ after cutting fruits. Five samples are shown per sampling date. Each sample was printed on a plate twice in the same square. The samples were oriented with the pedicel toward the top of the gel. Fruits cut 15 Aug.

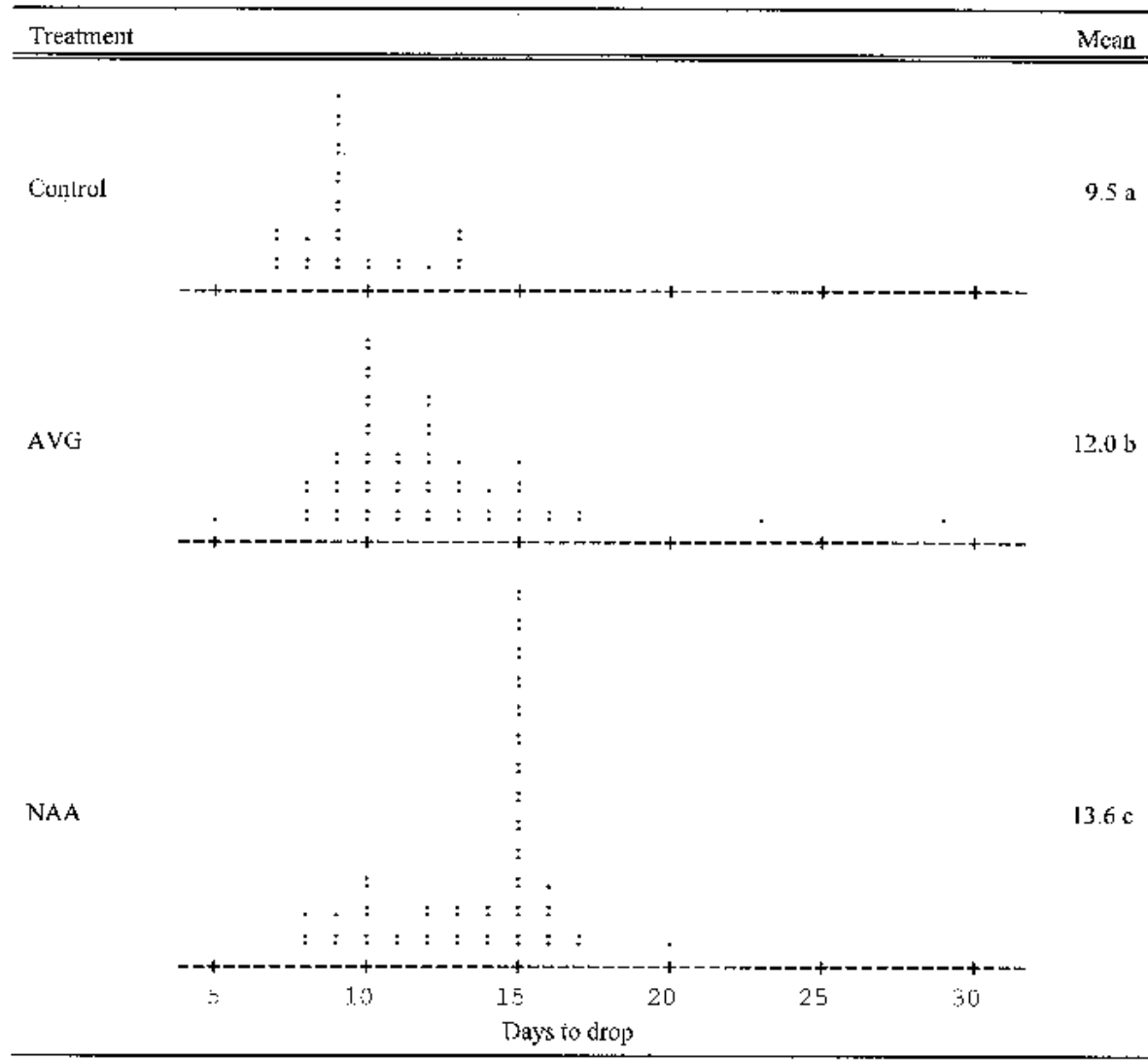

Fig. 2. Frequency distribution plots and means of days from cutting to drop for 'Delicious' fruits on nontreated control limbs and on limbs sprayed with AVG $\left(652 \mathrm{mg} \cdot \mathrm{L}^{-1}\right)$ or NAA $\left(10 \mathrm{mg} \cdot \mathrm{L}^{-1}\right)$. Means followed by different letters are significantly different at $P \leq 0.05$ according to contrasts. Each dot represents one fruit. Data for the 2- and 4-d treatments were pooled for AVG and NAA treatment, as timing differences were nonsignificant. quick, simple, inexpensive, and provide information on tissue-level localization and relative activity of cellulase over time. The rapidity of the assay allows the use of many samples directly from the orchard. These assays could be used to identify enzyme activities of separating cells in other organs or at other times of year.

Effects of applying growth regulators after induction. The noncut control fruit dropped more than 3 weeks later than did cut fruits (mean days to drop $=36.7$ ). The data were significantly more variable than the other treatments and were therefore excluded from further analysis and are not presented. Treatment with AVG or NAA delayed abscission of cut fruit (Fig. 2). Data for treatment 2 and $4 \mathrm{~d}$ after cutting did not differ significantly, nor did date interact with growth regulator treatment. Both compounds delayed fruit drop, but NAA delayed drop $1.6 \mathrm{~d}$ longer than did AVG (Fig. 2).

The plate assay suggested that cellulase activity in the AZ increased $4 \mathrm{~d}$ after cutting fruits. Growth regulator treatments were applied $2 \mathrm{~d}$ before and the day when increased CM-cellulase activity was detected. Foliar sprays of both NAA and AVG delayed abscission even after cellulase activity had increased (Fig. 2), but NAA was more effective than AVG. Commercial application of AVG to reduce preharvest drop is normally made 4 weeks before anticipated harvest. In this study, treatments were applied near the time of harvest to investigate the possibility of delaying abscission after the abscission process had begun. Applications of NAA to reduce preharvest drop are often made as few as 7 to $10 \mathrm{~d}$ before anticipated harvest, hence NAA may be more effective at delaying fruit drop late in the progress of developmentally programmed abscission.

The distributions of the days to drop differed for all three treatments (Fig. 2). The skewness coefficient is a nondimensional measure of the degree and direction of asymmetry of a distribution. Treatment with AVG caused the distribution to be strongly skewed to the right $($ skew $=2.18)$, controls were skewed slightly to the right (skew $=0.28$ ), and the NAA treatment was skewed slightly to the left (skew $=-0.59$ ) (Fig. 2). Many of the AVGtreated fruit fell shortly after the controls dropped, with abscission of the remaining fruit spread over a longer time than that of the NAA-treated fruits. Some fruits may have entered the climacteric and have already begun to synthesize ethylene autocatalytically at the time of treatment. Application of AVG this late may therefore have been less effective because of its reduced ability to attenuate ethylene levels in fruits already synthesizing ethylene.

\section{Literature Cited}

Bonghi, C., N. Rascio, A. Ramina, and G. Casadoro. 1992. Cellulase and polygalacturonase involvement in the abscission of leaf and fruit explants of peach. Plant. Mol. Biol. 20:839-848.

del Campillo, E., P.D. Reid, R. Sexton, and L.N. 
Lewis. 1990. Occurrence and localization of a 9.5 cellulase in abscissing and nonabscissing tissues. Plant Cell 2:245-254.

Horton, R.F. and D.J. Osborne. 1967. Senescence, abscission and cellulase activity in Phaseolus vulgaris. Nature 214:1086.

Marini, R. and R. Byers. 1988. Methods for evaluating chemical inhibitors of apple abscission. HortScience 23:849-851.

Pandita, V.K. and K.K. Jindal. 1991. Enzymatic and anatomical changes in the abscission zone cells of apple fruits induced by ethephon. Biol. Plant. 33:20-25.

Ramina, A., G. Casadoro, and N. Rascio. 1993. Structural, biochemical and molecular aspects of abscission in peach. Acta Hort. 329:211-217.

Saleh-Rastin, N., M. Petersen, S. Coleman, and D. Hubbell. 1991. Rapid plate assay for hydrolytic enzymes of Rhizobium, p. 188. In: D. Keister and P. Cregan (eds.). The rhizosphere and plant growth. Kluwer Academic. Dordrecht, The Netherlands.

Sexton, R. and J.A. Roberts. 1982. Cell biology of abscission. Annu. Rev. Plant Physiol. 33:133162

Tucker, M., G. Matters, S. Koehler, E. Kemmerer, and S. Baird. 1993. Hormonal and tissue-specific regulation of cellulase gene expression in abscission. Curr. Plant Sci. Biotech. Agr. 16:265271 